\title{
A double blind controlled trial of prednisolone-21- phosphate suppositories in the treatment of idiopathic proctitis
}

\author{
J. E. LENNARD-JONES, ${ }^{1}$ J. H. BARON, ${ }^{2}$ A. M. CONNELL, ${ }^{3}$ \\ AND F. AVERY JONES \\ From St. Mark's Hospital, London
}

EDITORIAL SYNOPSIS A double blind trial of prednisolone suppositories in out-patients with idiopathic proctitis is reported. Significant improvement was noted. When prednisolone suppositories were given after the patient had already used suppositories of base alone for three weeks the active treatment was no longer so effective.

Local treatment of idiopathic proctitis with suppositories containing corticosteroids was described by Truelove (1959). He treated 22 patients with suppositories containing $10 \mathrm{mg}$. of hydrocortisone hemisuccinate or $5 \mathrm{mg}$. of prednisolone-21phosphate. In 14 patients relief of symptoms was rapid and complete, usually with corresponding improvement in the sigmoidoscopic appearances. As this trial was uncontrolled and as idiopathic proctitis frequently undergoes spontaneous improvement (Lennard-Jones, Cooper, Newell, Wilson, and Avery Jones, 1962), we have extended Truelove's observations by carrying out the following double blind controlled trial.

DESIGN OF TRIAL

Two comparisons were made: between the drug and control in two groups of patients in an initial three-week period and between the drug and control in two successive three-week periods in the same patient when there was no response to the initial treatment.

SELECTION OF PATIENTS The patients selected for the trial were all out-patients suffering from active idiopathic proctitis as defined by Lennard-Jones et al. (1962). All experienced rectal bleeding which was not improving spontaneously, and active or moderately active inflammation of the rectal mucosa was seen on sigmoidoscopy. A clear upper limit to the inflammation was visible using

'Late member, Medical Research Council, Department of Clinical Research, University College Hospital Medical School, London.

${ }^{2}$ Late Leverhulme research scholar, Institute of Clinical Research, Middlesex Hospital Medical School, London.

${ }^{3}$ Member, Medical Research Council, Gastroenterology Research Unit, Central Middlesex Hospital. a $25 \mathrm{~cm}$. Lloyd-Davies sigmoidoscope. Patients were excluded from the trial if there was $x$-ray evidence of disease involving the colon (in nine patients a barium enema was not performed because of the mild nature of the symptoms). Patients were also excluded from the trial if they had received prednisolone-21-phosphate suppositories during the previous three months.

ALLOCATION OF PATIENTS TO DIFFERENT TREATMENTS At the first visit each patient selected for the trial was given a prescription as follows: 'Prednisolone-21-phosphate suppository trial, two nightly for three weeks.' Treatments were allocated by the pharmacist in a random order so that the patient received either suppositories consisting of an unmedicated, partially hydrogenated wax or suppositories of the same base each containing prednisolone-21-phosphate, $5 \mathrm{mg}$. If the symptoms did not improve within three weeks, the patient was told that the treatment would be changed. He was given the alternative suppository and the trial continued for a further three weeks.

ASSESSMENT OF RESULTS Symptoms were classified at the end of each treatment as 'no change or worse', 'improved', or 'no symptoms'. Sigmoidoscopic appearances before and after treatment were graded as 'active', 'moderately active', 'inactive', or 'normal', as described by LennardJones, Longmore, Newell, Wilson, and Avery Jones (1960).

THE TREATMENT GROUPS There were 46 entries to the trial: 44 patients entered the trial once and two patients ${ }^{4}$

These two patients were admitted twice because of the paucity of suitable patients presenting for treatment. Their inclusion theoretically necessitates a more complicated statistical analysis of the results than has been made; but in view of the extent of the differences reported this complication has been ignored. One patient received activesuppositories twice, the other received first active and second control suppositories. 
TABLE I

COMPARABILITY OF THE TREATMENT GROUPS

\begin{tabular}{lccccc} 
& $\begin{array}{l}\text { No. of } \\
\text { Patients }\end{array}$ & Mean Age & Males & \multicolumn{2}{c}{$\begin{array}{c}\text { Total History } \\
<\text { One Year }\end{array}$} \\
\hline Prednisolone & 16 & 41.6 & 10 & 6 & 4 \\
Control & 23 & 40.5 & 11 & 4 & 9
\end{tabular}

entered the trial on two occasions for different relapses of proctitis. Of the 46 entries to the trial, 25 were randomly allocated to the control and 21 to the active suppository. Results are not available for all these patients as four (one control, three active) were later excluded because their disease was found to extend beyond the rectum and three (one control, two active) did not attend for follow-up examination. Details of the patients for whom results are available are set out in Table I.

\section{RESULTS}

RESULTS OF FIRST TREATMENT Figure 1 shows the change in the patient's symptoms and Fig. 2 the change in the sigmoidoscopic appearances after treatment. It will be seen that 14 of the 16 patients given prednisolone improved symptomatically and 12 improved sigmoidoscopically. One patient was not sigmoidoscoped. In contrast, of the 23 patients given the control suppository, only nine improved symptomatically and nine sigmoidoscopically. These differences between the results of treatment with the two suppositories are significant as regards both symptoms $(P<0.01)$ and sigmoidoscopic appearances $(P<0.05)$.

The symptomatic and sigmoidoscopic improvements do not always correspond. The initial haemorrhagic 'active' appearance of the rectal mucosa was replaced by the 'inactive' phase in only four of the nine patients who were free of symptoms after treatment with the active suppository and one of the two patients free of symptoms after receiving the control treatment.

At the end of three weeks' treatment with prednisolone five out of six patients who had a history of less than one year had no symptoms whereas only four out of 10 patients whose history was longer than one year were free of symptoms at that time. In the control group, three of the four patients with a history of less than one year were unchanged at the end of three weeks.

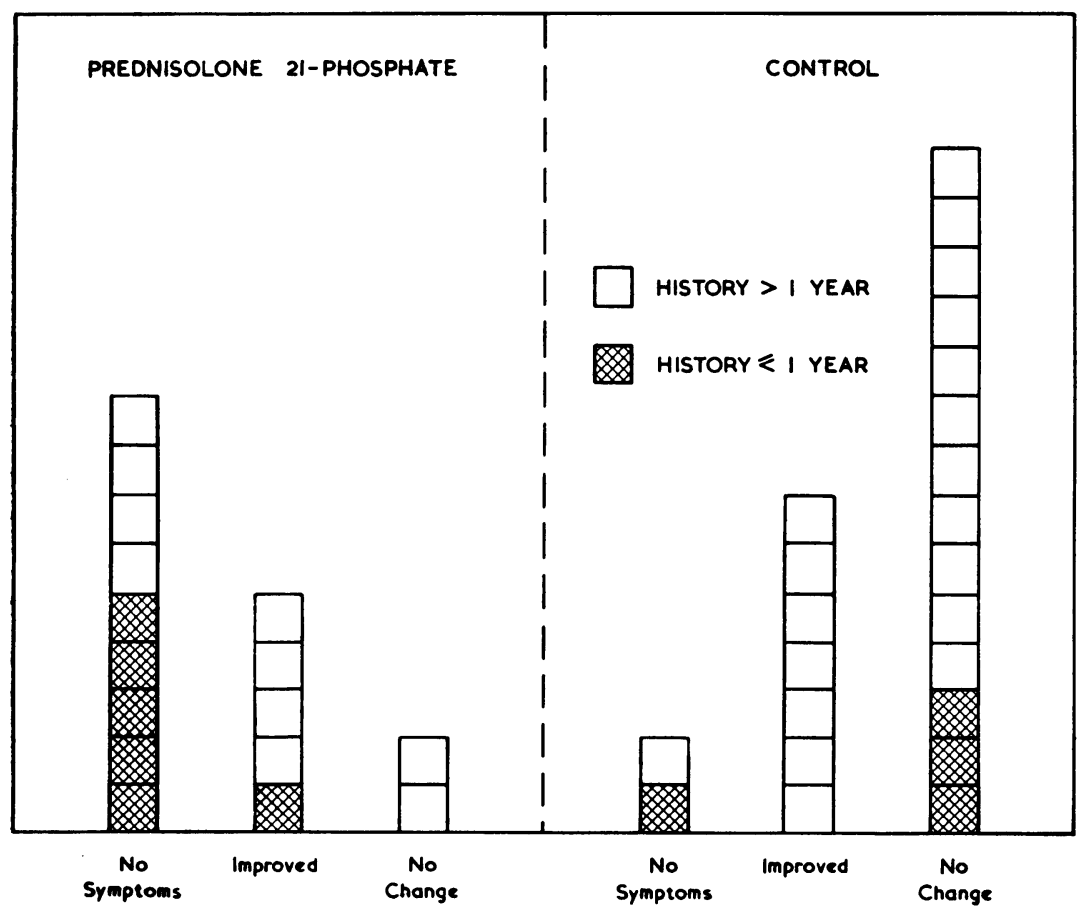

FIG. 1. Symptoms after treatment for three weeks. Improvement occurred significantly more often in the prednisolone-treated group than in the control group $\left(\chi_{\mathrm{c}}^{2}=7 \cdot 23, n=1\right.$, $0.001<P<0.01)$. 


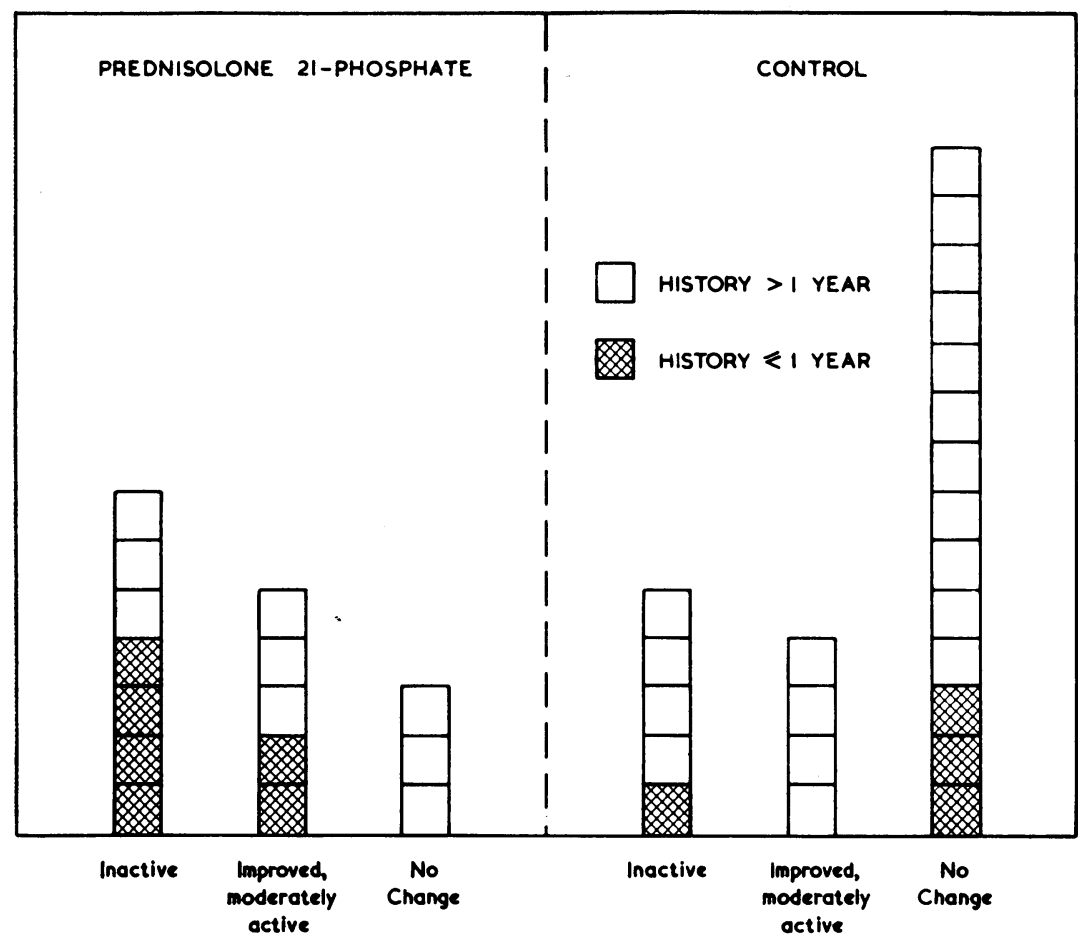

FIG. 2. Sigmoidoscopic appearances after treatment for three weeks.

Improvement occurred significantly more often in the prednisolone-treated group than in the control group $\left(\chi_{\mathrm{c}}^{2}=4 \cdot 59, n=1\right.$, $0.02<P<0.05)$.

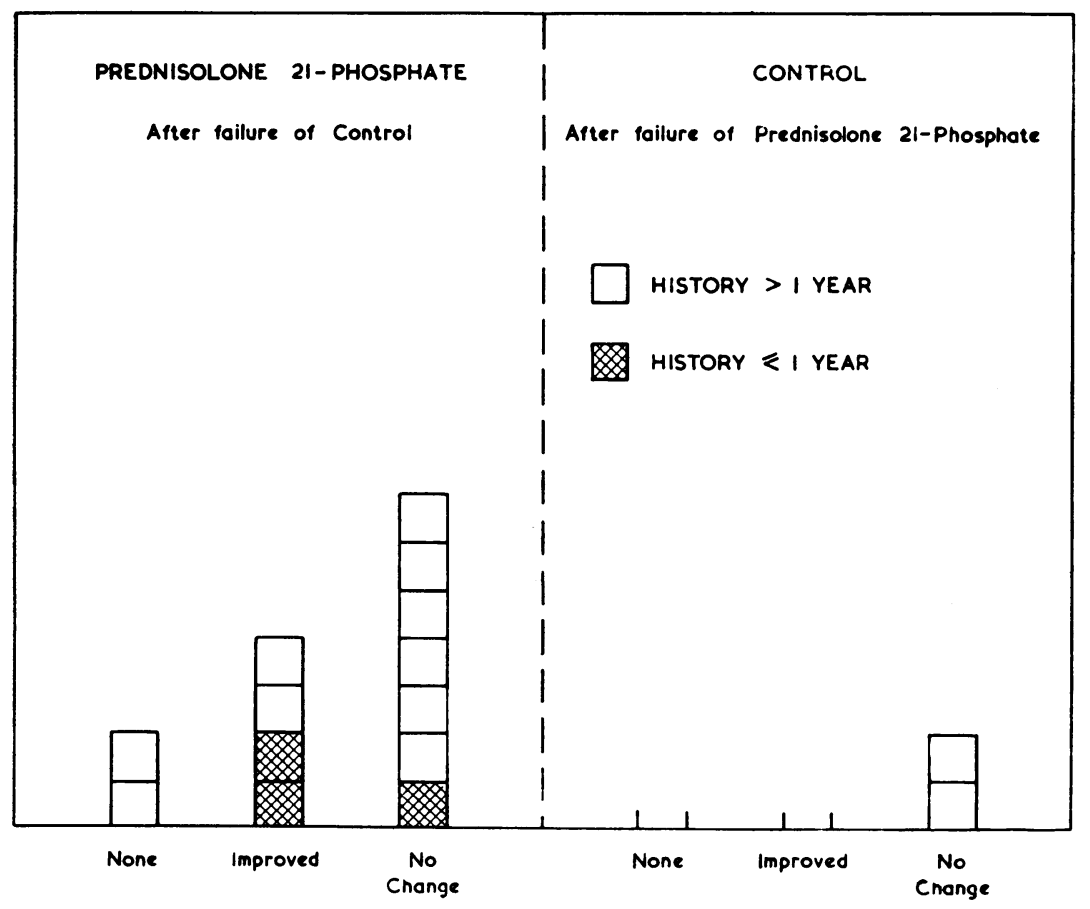

FIG. 3. Symptoms after second three-week treatment after failure of first treatment. 


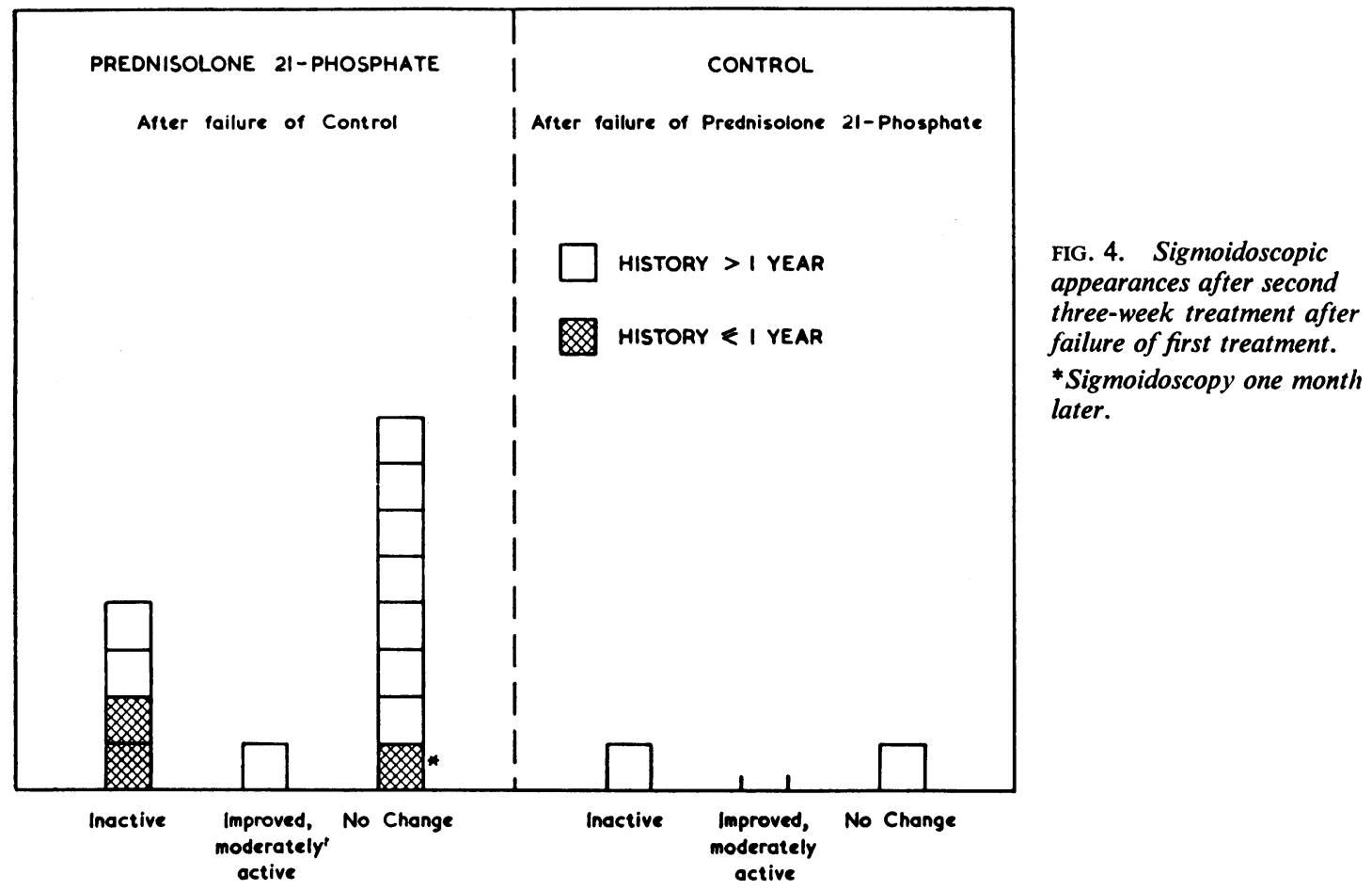

RESULTS OF ALTERNATIVE TREATMENT Figures 3 and 4 show the change in symptoms and sigmoidoscopic appearances of 15 patients whose symptoms had not improved during the first three weeks' treatment and who were then given alternative treatment. It will be seen that of the 13 patients now receiving prednisolone, only six improved symptomatically and five sigmoidoscopically. In no case was the disease in complete symptomatic and sigmoidoscopic remission after three weeks' treatment.

\section{DISCUSSION}

These results confirm Truelove's (1959) finding that suppositories containing prednisolone-21-phosphate improve the symptoms of most patients with idiopathic proctitis. However, symptomatic and sigmoidoscopic remission within three weeks was complete in only one quarter of the patients in this series. As Truelove (1959) found, prednisolone suppositories are most effective in patients with a history of less than one year, but, in this series, symptomatic and sigmoidoscopic remission was not complete in every case. Table I shows that in this series six of the 16 patients in the prednisolone group and only four of the 23 patients in the control group gave a history of less than one year. It is possible that this distri- bution weights the trial in favour of the active treatment, though this does not seem likely as results in the control group appear independent of length of history. In addition, among those given the active treatment results were favourable both in those with a long and those with a short history. Surprisingly, most patients who were given prednisolone suppositories as the second treatment after the failure of control suppositories did not improve. This failure suggests that the initial three weeks' treatment with the suppository base alone lessened the chance of a subsequent response to prednisolone.

We thank Nurse James and Miss Allen, B.Pharm., for their help and Mrs. I. M. Prentice for the illustrations.

We thank Glaxo Laboratories Ltd. for the preparations used in this trial.

\section{REFERENCES}

Lennard-Jones, J. E., Cooper, G. W., Newell, A. C., Wilson, C. W. E., and Jones, F. Avery (1962). Observations on idiopathic proctitis. Gut, 3, 201.

- Longmore ,A. J., Newell, A. C., Wilson, C. W. E., and Jones, F. Avery (1960). An assessment of prednisone, salazopyrin, and topical hydrocortisone hemisuccinate used as out-patient treatment for ulcerative colitis. Ibid, 1, 217-222.

Truelove, S. C. (1959). Suppository treatment of haemorrhagic proctitis. Brit. med. J., 1, 955-958. 